\title{
Future Aircraft and the Future of Aircraft Noise
}

\author{
Karsten Knobloch, Eric Manoha, Olivier Atinault, Raphaël Barrier, \\ Cyril Polacsek, Mathieu Lorteau, Damiano Casalino, Daniele Ragni, \\ Gianluca Romani, Francesco Centracchio, Monica Rossetti, Ilaria Cioffi, \\ Umberto Iemma, Vittorio Cipolla, Aldo Frediani, Robert Jaron, \\ and Lars Enghardt
}

\begin{abstract}
In order to cope with increasing air traffic and the requirement to decrease the overall footprint of the aviation sector-making it more sustainably and acceptable for the whole society-drastic technology improvements are required beside all other measures. This includes also the development of novel aircraft configurations and associated technologies which are anticipated to bring significant improvements for fuel burn, gaseous and noise emissions compared to the current state and the current evolutionary development. Several research projects all over the world have been investigating specific technologies to address these goals individually, or novel—sometimes also called "disruptive" — aircraft concepts as a whole. The chapter provides a small glimpse on these activities - mainly from a point of view of recent European funded research activities like Horizon2020 projects ARTEM, PARSIFAL, and SENECA being by no-way complete or exhaustive. The focus of this collection is on noise implications of exemplary novel concepts as this is one of the most complicated and least addressed topics in the assessment of aircraft configurations in an early design stage. Beside the boundary layer ingestion concept, the design process for a blended wing body aircraft is described, a box-wing concept is presented and an outlook on emerging supersonic air transport is given.
\end{abstract}

Giving some views on possible future civil aircraft architectures_including supersonic ones-and the possible consequences on noise at source

K. Knobloch $(\bowtie) \cdot$ R. Jaron $\cdot$ L. Enghardt

Department Engine Acoustics, German Aerospace Center (DLR), 10623 Berlin, Germany

e-mail: Karsten.Knobloch@dlr.de

E. Manoha $\cdot$ O. Atinault $\cdot$ R. Barrier $\cdot$ C. Polacsek $\cdot$ M. Lorteau

ONERA-The French Aerospace Lab-Centre de Châtillon, Department of d'Aérodynamique,

Aéroélasticité et Acoustique (DAAA), 92322 Châtillon Cedex, France

D. Casalino · D. Ragni · G. Romani

TU Delft, Faculty of Aerospace Engineering, 2629 HS Delft, The Netherlands

F. Centracchio $\cdot$ M. Rossetti $\cdot$ I. Cioffi $\cdot$ U. Iemma

Department of Engineering, Università Degli Studi Roma Tre, 00146 Roma, Italy

V. Cipolla $\cdot$ A. Frediani

Department of Civil and Industrial Engineering, University of Pisa, 56126 Pisa, Italy

(C) The Author(s) 2022

117

L. Leylekian et al. (eds.), Aviation Noise Impact Management,

https://doi.org/10.1007/978-3-030-91194-2_5 
Keywords Future aircraft configurations - Aircraft noise $\cdot$ Noise characteristics Aircraft design for civil airliners $\cdot$ Noise reduction $\cdot$ ARTEM

\section{The Need for Novel Aircraft Configurations}

\section{Karsten Knobloch}

Air travel is undoubtedly one of the great achievements of scientists, engineers, and many different professions which make the whole system of today's air transport running smoothly. Business and leisure travel connecting almost all parts of the world and affordable prices for a large part of the population - at least in developed countries - brings literally "the world together".

However, the constant increase in passengers traveling, number of aircrafts and number of flights is directly connected to some drawbacks, which are inherent to all traffic systems: increase in resource consumption (e.g. fuel), absolute increase of emissions, and increased annoyance from air traffic related noise. Although aviation was accountable for only $3.6 \%$ of the total greenhouse gas (GHG) emissions in EU28 area [1], it is ranked second for transport related GHG emissions after road traffic, and of increasing relevance with non-transport sources of GHG emissions declining [2]. The European Aviation Environmental Report 2019 [3] stated an increase of total passenger kilometers (departures from EU28 + EFTA states) of $60 \%$ between 2005 and 2017, an increase of people within $55 \mathrm{~dB}\left(\mathrm{~L}_{\mathrm{DEN}}\right)$ noise contours around airports of $12 \%$, despite a decrease of average noise per flight of $14 \%$ in the same time frame. The overall fuel consumption increased between 2005 and 2017 by $16 \%$ while the average fuel consumption (per passenger kilometer) decreased by $24 \%$.

This strongly underlines the constant technology development towards more efficient, less fuel-consuming and less noisy aircrafts, introduction of improved flight procedures, efficient management practices, and the effect of fleet renewal. However, the pace of evolutionary improvements - in the past based to a large extent on improved aircraft engine technologies - is not sufficient to counterbalance current and expected future growth of air traffic.

It is worth underlining that the period in which this book is written is characterised by the outbreak of the COVID-19 virus, which in addition to the worldwide health emergency, has caused an economic crisis that has curtailed the air traffic. According to observers from international organisations such as IATA [4] or ICAO [5], although the shock introduced by the pandemic is changing the global air traffic market in the short-term, air transport will recover its positive growth rate, hence, soon the environmental impact of aviation will be again a priority.

With this short general examination of the recent past and the current situation of the air transport sector it becomes clear that significant improvements in all connected disciplines are required to counterbalance the expected growth and beyond: to decrease the footprint of aviation in terms of use of resources, emissions, and noise exposure. 
This chapter focuses on the impact of aircraft technology, specifically novel aircraft configurations which differ from the tube-and-wing design of almost all current commercial aircraft. While some of these "novel" configurations have been discussed already for quite some time, usually the focus of past assessment was on specific benefits (e.g. fuel consumption) of the respective configuration-neglecting other important aspects which need to be addressed as well for a successful aircraft development process. A detailed assessment of expected aerodynamic performance, flight mechanics, fuel burn, and emitted noise already in an early stage of the design process is of utmost importance to initiate further activities in the long-lasting, expensive, and complicated process of the design and introduction of a completely new aircraft. The focus here is on noise implications of exemplary novel concepts as this is one of the most complicated and often least addressed topics in the assessment of aircrafts at concept stage. The selected activities-being by no-way complete or exhaustive-are based on recent and on-going EC funded research activities.

In particular, following four topics are addressed in this chapter:

- A new propulsion concept using embedded engines (BLI) on an otherwise nearly conventional tube-and-wing aircraft design is described and its implications on noise is assessed.

- A Multidisciplinary Conceptual Robust Design Optimisation (MCRDO) framework is described which gives a good impression of the complexity and interactions of the individual disciplines in an aircraft design process. An application of this framework for the design of two novel aircraft blended wing aircraft configurations is described as well.

- The box-wing concept - aiming at an improved aerodynamic performance - as explored within the recent H2020 project PARSIFAL is presented briefly and major project results are described.

- Finally, a further spotlight is shed on developments for super-sonic civil air transport - which is expected to resume in the near future. The latter does not imply the expectation for positive contributions of supersonic transport to the desired reduction in noise and resource consumption, but shall provide a short overview of current worldwide activities which are expected to influence the air transport sector and aircraft noise of the future.

Activities on the first two topics have been carried out within ARTEM, an EC funded Horizon2020 project started in 2017 and running until 2022 (grant number 769350). In ARTEM, partners from research centers, industry, and academia joint in order to help closing the gap between noise reductions obtained by current technologies - as already applied or being matured in large EU technology projects such as OpenAir and CleanSky - and the long-term goals of ACARE, i.e. a noise reduction of $65 \%$ for each aircraft operation in year 2050 compared to the reference year 2000 value.

The main topics of ARTEM are novel liner concepts and metamaterials capabilities for reduction of noise propagation, the reduction of noise generation itself by understanding, reducing, or tailoring component interactions, and the prediction and assessment of the effect of these noise reduction measures on aircraft level. The aim 
is to develop these "Generation 3" noise reduction technologies (NRTs) to a technology readiness level (TRL) of 3 (experimental proof of concept) to 4 (technology validated in lab).

The application of noise reduction technologies depends strongly on the aircraft configurations itself which requires the detailed consideration of potential future configurations. This was the reason to implement a specific work package within ARTEM dealing with the assessment of technologies on novel aircraft configurations, starting with a detailed definition of these configurations. The noise signature of the anticipated configurations will be strongly influenced by the interaction of several aircraft components: the interaction of airframe, high-lift-system, and propulsive jet of the engine(s), the interaction of airframe and engine inlet, the interaction of the landing gear with the airframe. These effects - which directly involve the noise generation - are investigated in the ARTEM framework by dedicated experiments and high-fidelity numerical calculations. The development of tools, their validation, and their application to investigate noise reduction potential of certain technologies is the major output of ARTEM.

The following subsections thereby highlight selected topics which are typical for many potential future aircraft concepts - while others had to be neglected for the sake of conciseness.

\section{Boundary Layer Ingestion and the NOVA Concept: Implications on Noise}

\section{Eric Manoha, Olivier Atinault, Raphaël Barrier, Mathieu Lorteau, Cyril Polacsek}

\section{Damiano Casalino, Daniel Ragni, Gianluca Romani}

In the last few decades, the constant strive for lower noise and fuel consumption of transport aircraft has led to a significant increase of the bypass ratio of coaxial turbofan engines, resulting in an increased fan and nacelle diameter. This tendency now reaches its limit for turbofan engines conventionally installed under the wing. An alternative is to partly bury the engine, in the rear fuselage for conventional tube-andwing aircraft or above the airframe for more innovative blended wing body aircraft. The theoretical propulsive benefit of this "boundary layer ingestion" relies on the reduction of the exhaust jet wasted kinetic energy and filling-in the airframe wake velocity defect. Another positive consequence, beyond the reduction of the exposed frontal area of the aircraft, is the reduction of the overall aircraft mass and drag, due to the nacelle pylon removal and the lower wetted surface area. On the acoustic point of view, a potential noise reduction is expected from the partial or total shielding of the fan/OGV (outlet guide vane) noise sources by the airframe, as long as the amplitude of these noise sources does not significantly increase with respect to a conventional podded implementation, due to the space-time distortions of the flow 

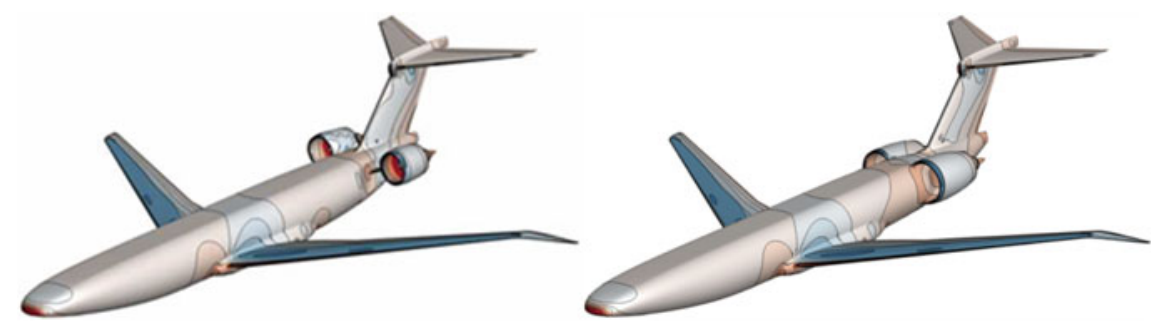

Fig. 1 NOVA aircraft configurations: conventional w.rear fuselage engines and BLI configuration

ingested by the fan. Up to now, the acoustic balance between these opposite effects of the BLI concept had not been assessed.

\section{The NOVA Aircraft}

In this general context, ONERA has designed the NOVA (Next generation ONERA Versatile Aircraft), which integrates the best available technologies for optimal propulsive performances. NOVA's architecture includes a wide lifting fuselage and a wing with high aspect ratio and downward oriented winglets [6, 7]. A modern ultra-high bypass ratio (UHBR) engine with bypass ratio of 16 has been specifically designed and implemented in several NOVA versions, either conventional (in isolated nacelles implemented under-wing or at rear fuselage) or semi-buried in the rear fuselage side, ingesting the boundary-layer developed along the whole fuselage length (Fig. 1).

Through several projects, these NOVA versions have been subjected to intensive aerodynamic numerical simulations by ONERA to compare their global propulsive performances.

\section{ARTEM Objectives and Work Sharing}

In ARTEM, the objective pursued by ONERA and the Technical University of Delft (TU-Delft) was to tentatively assess the acoustic performances of the NOVA aircraft versions, and especially to evaluate the impact of the BLI configuration on the overall noise through comparisons to the other more conventional configurations where the engine is considered as isolated. A secondary aim was to evaluate up-to-date numerical simulation methods, including the generation of aeroacoustic noise sources in the local aerodynamic flow field and the noise propagation to the far field, accounting for the shielding effects.

The global issue of aircraft noise is especially critical in the airport areas, at take-off and landing. At high altitude/speed, the noise from conventional aircraft 
perceived on the ground is typically not an issue, but it could become one, depending on possible noise increase generated by the BLI implementation. Following this dual objective, TU-Delft and ONERA have addressed the acoustic assessment of the BLI at respectively low speed (take-off) and high speed (cruise).

\section{Acoustic Assessment at Low Speed}

TUDelft's investigated the broadband and tonal noise generated by the fan embedded in BLI configuration, accounting for the turbulent flow developing over the fuselage at take-off with power cut-back. Due to confidentiality constraints on the BLI implementation designed by ONERA, the analysis used a generic benchmarked engine, the Low-Noise NASA Source Diagnostic Test (SDT), both isolated and integrated in BLI configuration. For this comparison, a global rescaling of the engine diameter and the nacelle length was required. Moreover, for the BLI version, the difficult design of an S-duct generating reasonable fan inflow was also needed (Fig. 2).

The numerical flow solution was obtained with the LBM (Lattice-Boltzmann method) solver 3DS Simulia PowerFLOW ${ }^{\circledR}$. Then, the acoustic far-field was computed by using a FW-H (Ffowcs-Williams and Hawkings) integral solution from a permeable integration surface which encompassed the engine and a portion of the fuselage to partially take into account the acoustic scattering on the aircraft. The other installation effects due to the non-uniform BLI were implicitly taken into account by the installed engine simulation, as in Fig. 2. Compared to the isolated implementation, the BLI fan-stage is characterised by strong in-plane azimuthal velocity and blade loading fluctuations, and non-axisymmetric and incoherent rotor wakes. This results in far-field noise spectra with no distinct tonal components and high broadband levels. In Effective Perceived Noise levels, the BLI case turned out to be noisier than the isolated one, by $4 \mathrm{EPNdB}$ at front side and $18 \mathrm{EPNdB}$ at aft side (Fig. 3, see also [8]). A detailed analysis of the local aerodynamic flow field shows that the increase in noise results from a strong separation induced by the S-duct in the fan-stage rotor. This confirmed the necessity of a coupled optimisation of the blade loading with the duct shape to expect reasonable performances of the ducted configuration compared to the isolated one. This work in ARTEM sets one of the first
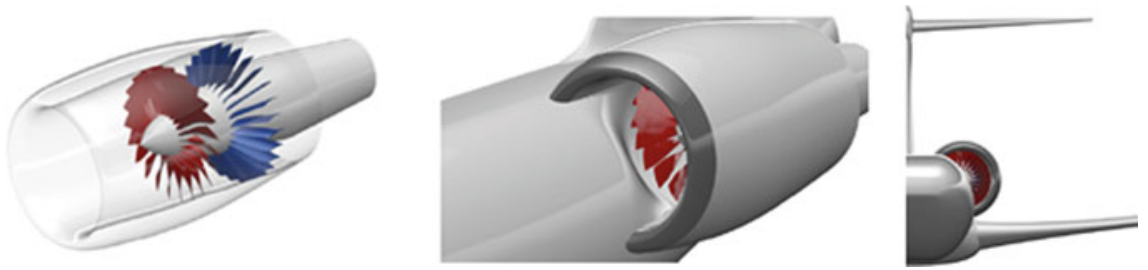

Fig. 2 NASA-SDT generic engine: isolated nacelle and BLI implementation in NOVA aircraft 

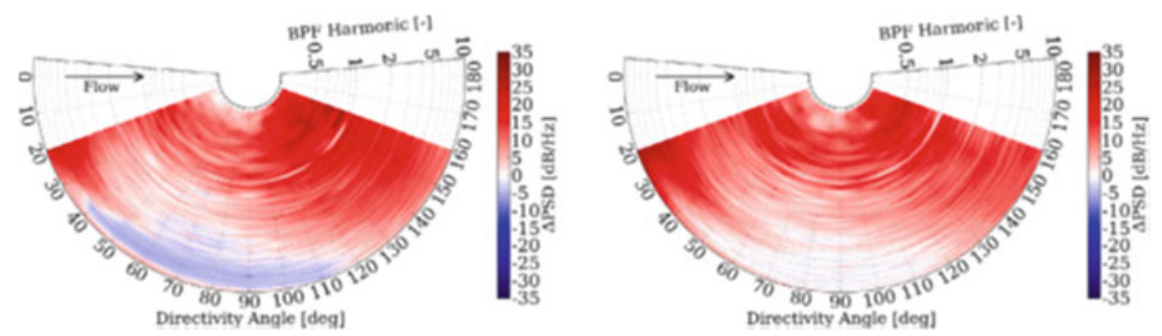

Fig. 3 Far-field noise directivity on ground arc (left) and sideline arc (right) centered around the fan, difference between BLI and isolated engine

Fig. 4 Mean axial velocity $(\mathrm{m} / \mathrm{s})$ over an iso-radial cut at $50 \%$ height for BLI case

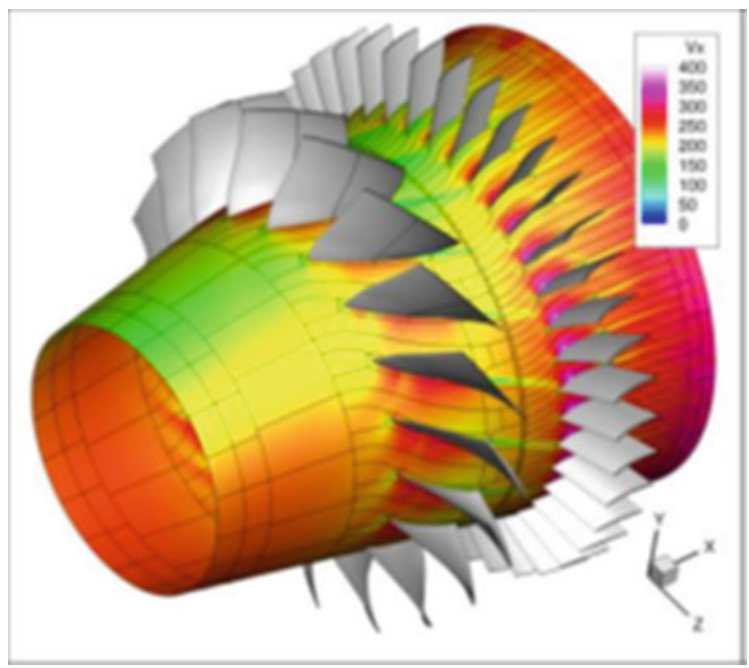

demonstrations of such a necessity to match combined aerodynamic and aeroacoustic constraints for the BLI propulsion concept.

ONERA investigated the tonal noise generated in cruise conditions in the intake and bypass duct of the turbofan engine specifically designed for the NOVA program, either implemented in BLI or isolated [9]. The harmonic loadings are inputted to an in-house FWH solver (ONERA FanNoise tool) adapted to annular duct propagation (Goldstein's formulation) [10].

\section{Acoustic Assessment at High Speed}

ONERA investigated the tonal noise generated in cruise conditions in the intake and bypass duct of the turbofan engine specifically designed for the NOVA program, 

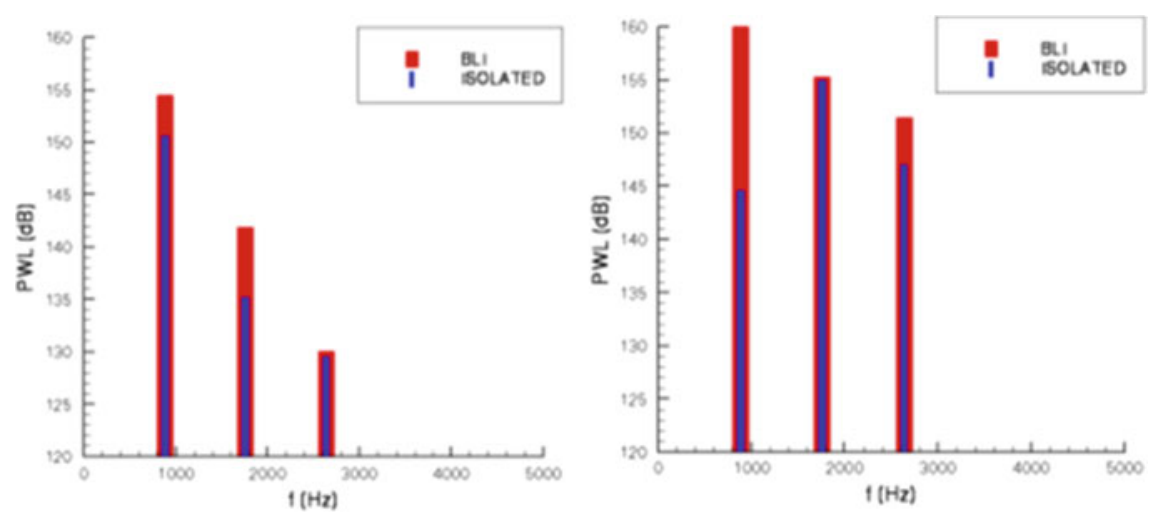

Fig. 5 Noise power spectra in the intake (BPF1 to BPF3) for baseline and BLI cases obtained from direct URANS (shockwaves, left) and assessed from FanNoise (rotor blade sources, right)

either implemented in BLI or isolated. fluctuations over blades/vanes provided by unsteady-RANS computations achieved with the elsA solver (Fig. 4).

At such transonic speeds, the blade tip Mach number is greater than one and shock waves propagate in the intake and contribute to the sound power, in addition to the loading noise generated by the flow interacting with the fan blades. Although the CFD mesh was not designed to ensure direct acoustic predictions, it has been found that the shocks are a dominant source at the blade passing frequency for the isolated case (sound power level PWL is $+6 \mathrm{~dB}$ higher than the one due to RSI noise) and might balance the BLI effects on the harmonic sound power levels generated in the intake by the fan/OGV loadings (see the PWL comparisons between Fig. 5 left and right). The BLI is responsible for an increase of $+6 \mathrm{~dB}$ of the overall PWL in the intake related to the RSI noise sources, that should be probably lower (around $+5 \mathrm{~dB}$ ) when including shocks contribution. Finally, harmonic loading noise from the OGVs in the bypass duct (expected to be a dominant source contribution in this region) gives rise to an increase of the OAPWL with BLI equal to $+5.5 \mathrm{~dB}$.

\section{Conclusions and Perspectives on the BLI Study}

This study presents original high-fidelity CFD/CAA simulations of a full-scale innovative aircraft concept comprehensive of a fan/OGV implemented in a BLI configuration. Both, at low speed (take-off) and high speed (cruise), a clear understanding is provided of the increase of the noise levels in BLI integrated configurations compared to more conventional podded turbofan installation. However all these results should be considered with the following reservations:

- At low speed, the study relies on the adaptation of a generic benchmarked engine, including the design "from scratch" of a new S-duct through a small number of 
iterations (due to limited project resources), leading to a strong flow separation ingested by the fan. It shows that such an optimised design is critical to minimise the impact on the BLI noise "penalty".

- At high speed, the method provides in-duct sound levels which reflect the source mechanism of fan/OGV interactions but do not account for any shielding effects by the S-duct and the airframe. Additionally, the completeness of this study should include an acoustic assessment at low speed of this BLI implementation designed by ONERA.

- Both studies at low and high speed do not include any passive or active flow/noise control technology that could significantly improve the acoustic characteristics of the BLI installation. Most promising passive devices include distortion-tolerant fan blades and acoustic liners in the S-duct. Beyond this, active technologies like smart adaptive blowing in the S-duct could counter inflow inhomogeneities and prevent flow separations and associated excess noise.

\section{FRIDA, a Framework for Innovative Design in Aeronautics}

\section{Francesco Centracchio and Umberto Iemma}

The tool FRIDA (FRamework for Innovative Design in Aeronautics) is the Multidisciplinary Conceptual Robust Design Optimisation (MCRDO) framework developed by the Aerospace Structures and Design group of Roma Tre University. FRIDA is a conceptual optimal design environment capable of addressing innovative, unconventional configurations taking into account objectives and constraints related to all the aspects typical of a long-term design, including the environmental sustainability, community acceptance and life-cycle costs. The framework can guarantee the robustness and reliability of the design in presence of uncertainties using different approaches to the quantification of the statistical properties of the solutions. The project was conceived at the end of the nineties in response to the growing interest of the aeronautical community in disruptive, environment-friendly configurations for civil aviation. The need for breakthrough solutions to cope with the increasing severity of the environmental constraints imposed a rethinking of the conceptual phase of the design, introducing prime-principle-based models to deal with the lack of empirical or analytical methods. FRIDA's ancestor academic tool MAGIC (Multidisciplinary Aircraft desiGn of Innovative Configurations [11]), although limited to the optimisation of the lifting system using local line-search schemes, was one of the first aeronautical MDO frameworks including a community noise module to define objectives and constraints related to the acoustic impact. MAGIC was conceived to handle the conceptual design of unconventional concepts, like the Prandtl-Plane (PP) or the Blended-Wing-Body (BWB) configurations [12]. The FRIDA project was initiated during the FP6 project SEFA (Sound Engineering For Aircraft, 20042007) as a breakthrough enhancement of MAGIC. The most important improvements introduced were the extension to global optimisation using heuristic methods, the enrichment of the noise module with source-related models as a complement to the 


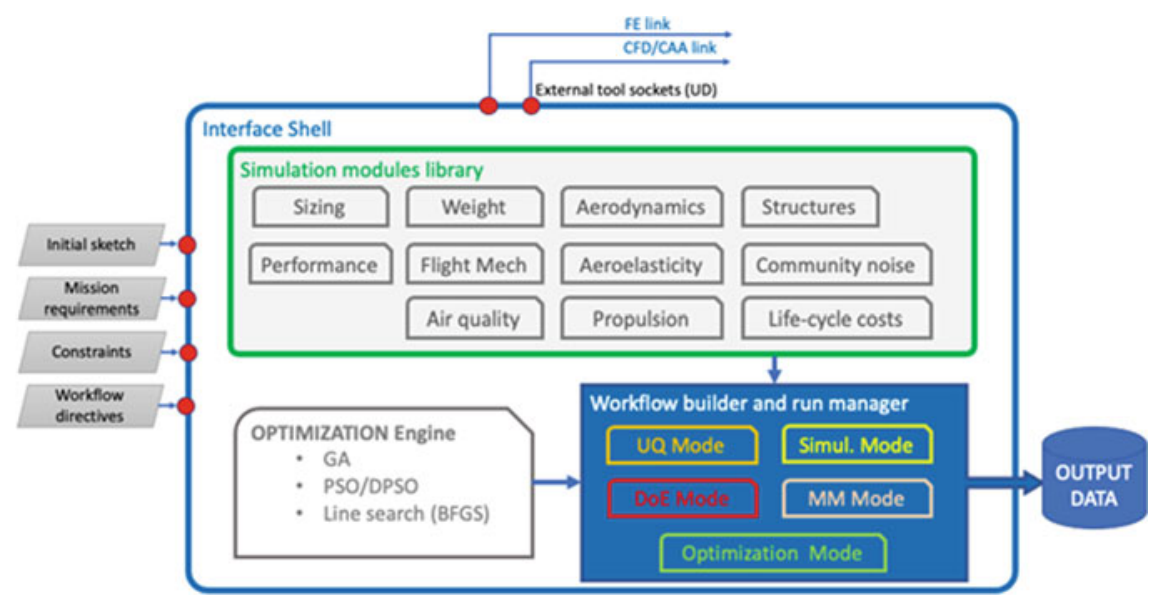

Fig. 6 Conceptual map of the FRIDA framework

classic noise-power-distance maps, and the development of an efficient parsing structure to make the framework easily expandable and linkable to external tools. These modifications made possible the first attempt of integration of sound-quality-based metrics in the design of an aircraft, opening the road towards the systematic use of perception-related objectives and constraints since the early conceptual phase ([1314a]). Over the following decade, FRIDA has been extensively used and improved within the context of FP7 and H2020 projects COSMA (FP7, 2009-2013), OPENAIR (FP7, 2009-2014), ANIMA (H2020, ongoing), and ARTEM (H2020, ongoing) in order to address the increasing complexity of the requirements with a state-of-the-art, multi-objective, robust and reliable approach suited to the most advanced SimulationBased Design Optimisation (SBDO) frameworks. The conceptual layout of FRIDA is depicted in Fig. 6. A parsing shell acts as an interface with the external world and manages the I/O structure, as well as the link with external simulation tools (under development). The Simulation modules library includes all the disciplines relevant for the design of a sustainable, innovative concept that can be activated through an appropriate description of the workflow. The Interface shell can be used to define at run time variables and parameters sets, allowing for a dynamic management of the design/analysis space. The optimisation core currently implements local linesearch methods (BFGS, CG), genetic algorithm and deterministic and stochastic particle swarm methods (PSO/DPSO). The accuracy level of the physical models implemented in FRIDA can capture the relevant physics of the phenomena involved along the entire aircraft flight envelope. The implemented algorithms are, whenever possible, prime-principle-based under specific assumptions to reduce the order of complexity. The overall computational cost turns out to be compatible with the high number of evaluations typical of an optimisation process. The framework is completed by a workflow builder and run manager in charge of the translation of the user directives in a well-defined workflow. An example of workflow used in the 


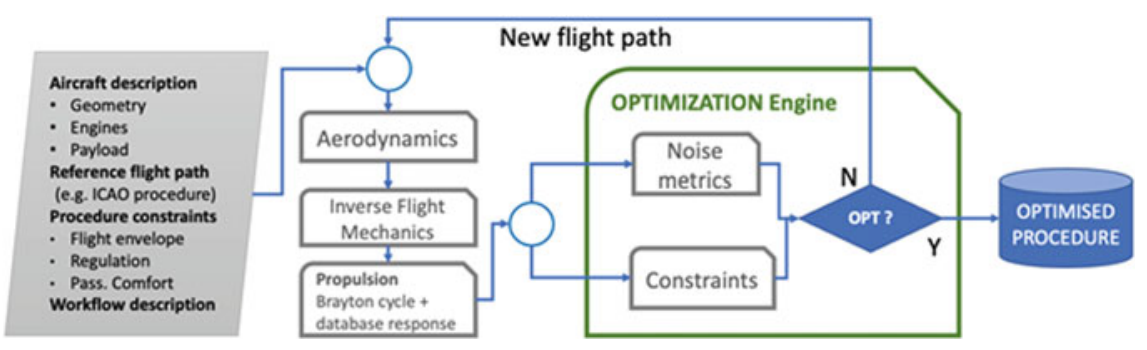

Fig. 7 FRIDA workflow used in ANIMA for optimisation of procedures

H2020 project ANIMA for the optimisation of Noise Abatement Procedures (NAP) is presented in the block diagram of Fig. 7. The modules activated are Aerodynamics, Inverse Flight Mechanics (calculates the aircraft settings for a given flightpath), and Propulsion (defines the engines rpm for a given thrust requirement using an in-house implementation of Brayton cycle coupled with a database of engines performance). The optimal flightpath is obtained using an evolutionary global optimiser (GA or PSO).

The Workflow Builder can combine any module to address a large variety of problems like quantification of uncertainties ( $U Q$ mode), design space exploration and design of experiment (DoE mode), or surrogate model definition (MetaModelling mode). Among the most recently introduced features, it is worth mentioning the link of the FRIDA flight simulation environment with the Flight-Gear (https://www.fli ghtgear.org/) simulation tool and the open flight-dynamics library JSBSIm (http:// jsbsim.sourceforge.net/). The interface is currently limited to the basic aerodynamic performance and the longitudinal dynamics of the aircraft. The full implementation of the JSBSim input format in the FRIDA I/O structure is under development. A preliminary example of a piloting session is available on a publication dedicated to "Flight simulation session of the HEP REBEL from ARTEM project" (https://doi. org/10.5281/zenodo.4650343, credits Marco Stefanini).

\section{Aircraft Design and Noise Prediction for Novel Concepts}

Francesco Centracchio, Monica Rossetti, Ilaria Cioffi and Umberto Iemma

The achievement of the ambitious noise reduction targets indicated in the ACARE Flightpath 2050 is subordinate to the identification of breakthrough solutions. Indeed, the simple progressive improvement of the current technologies wouldn't reach the level of noise abatement required to guarantee the quality of life of the community surrounding the airports in a scenario of a constantly growing market demand. One of the novel designs analysed and assessed in the project ARTEM is the Blended Wing Body (BWB) concept. It can be considered as a hybridisation of the flying 
wing concept, where the entire airframe generates lift, and a classic wide-body tubeand-wing aircraft, with the payload area located in a large central structure. The idea behind the concept consists in blending the wings and fuselage into a unified lifting surface, with a section of the large center body shaped like an airfoil. This configuration can be considered as unconventional in the context of civil aviation, even if the earliest designs of BWB airliners date back to the nineties. The main advantages of such a configuration are a high aerodynamic efficiency and the capacity to deploy a significant amount of lift for the same flying conditions. This results in a low consumption of fuel and the possibility to take off and land with a reduced use of the high-lift devices, which are responsible for a large portion of the aerodynamic drag and noise. An additional benefit of this configuration is obtained by the possibility to install the propulsion system on the top the center body and exploit the effect of shielding provided by the large surface of the payload-carrying structure. In the ARTEM project, three BWB configurations have been developed on the basis of two mission profiles: one regional/short range mission ( $<900$ nautical miles) and one long-haul profile of 5500 nautical miles. The long-range configuration denominated BOLT (Blended wing body with Optimised Low-noise Technologies) has been equipped with two last-generation UHBR turbofan engines, with an expected payload of 400 passengers in a two-classes cabin layout. The shortrange REBEL (REgional Blended-wing-body Electric-propelled), although originally conceived to be equipped with hybrid electric propulsion, has been actually designed in two versions: a baseline configuration equipped with conventional technologies and turbofan engines (REBEL-C) and the REBEL-HEP propelled by a distributed hybrid electric system [15-17]. A pictorial rendering of the ARTEM BWB fleet is presented in Fig. 8.

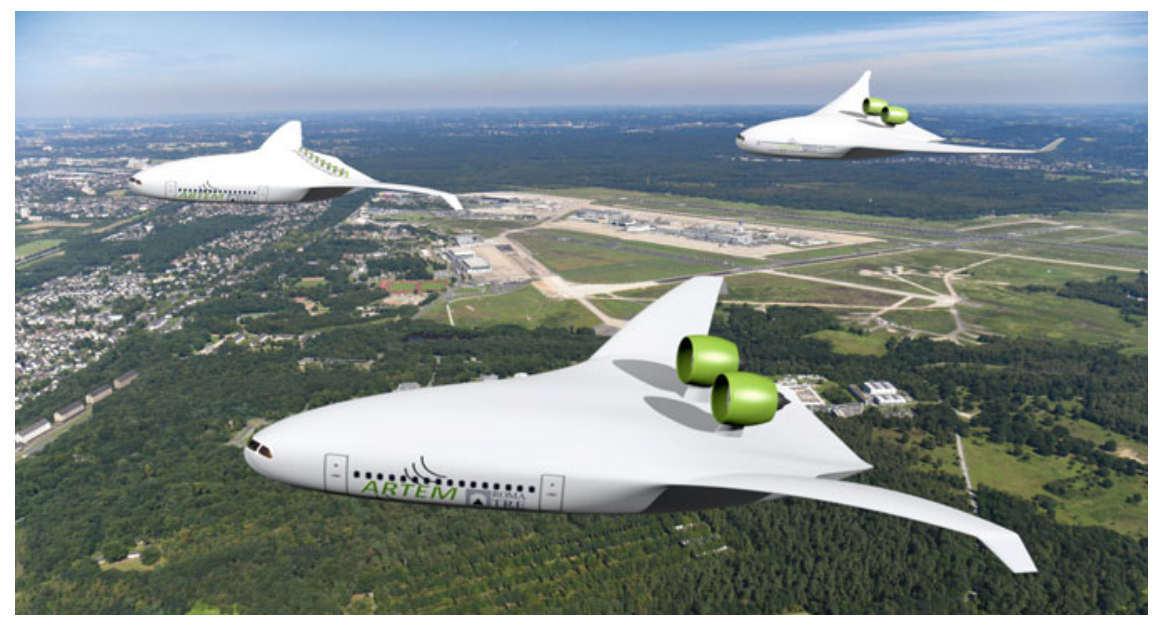

Fig. 8 Pictorial rendering of the ARTEM BWB fleet in flight 
The research activity performed within the framework of the ARTEM and ANIMA projects was devoted to the development and assessment of efficient and accurate models for the aeroacoustic assessment of this class of aircraft. A campaign of numerical simulations is foreseen in ARTEM using the analysis tools available at the Italian Center of Aerospace Research (CIRA, [18, 19]), whereas in ANIMA the Aerospace Structures and Design group of the Roma Tre University is in charge of the development of suitable surrogate models for the estimate of the shielding effect to be integrated in the design toolset [20-22].

Other ARTEM partners have used the BWB design for the assessment of noise shielding capabilities and improvement of models for the prediction of this effect. During the final project phase, the noise reduction technologies will be applied to the BWB configurations BOLT and REBEL, and by the subsequent simulation of flight trajectories the noise signature will be predicted and auralised for comparative listening tests.

\section{Benefits of the Box-Wing Architecture for Passenger Aircraft-The H2020 Project "PARSIFAL"}

\section{Dr. Vittorio Cipolla and Prof. Aldo Frediani}

PARSIFAL stands for "PrandtlPlane Architecture for the Sustainable Improvement of Future Airplanes". Funded by the EU under the Horizon 2020 Programme between 2017 and 2020, the PARSIFAL project has investigated the feasibility and performed a comprehensive impact assessment of the application of the box-wing architecture to short-to-medium range aircraft.

The box-wing configuration derives from the studies carried out in 1920s by Ludwig Prandtl, who described the box-wing, i.e. two horizontal wings connected at their tips by properly designed vertical wings (Fig. 9, left), as the "best wing system". According to Prandtl studies published in 1924 [23], in fact, among all the possible lifting systems the box-wing is the one capable to minimise the induced drag, once lift and wingspan are given. In order to pay tribute to Prandtl, the research team from University of Pisa, that in the 1990s started to study the engineering application of

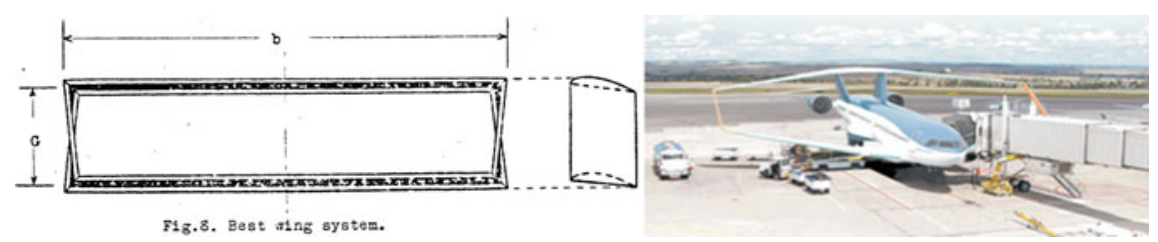

Fig. 9 Prandtl's "best wing system" (left) and the PrandtlPlane object of study of the project PARSIFAL (right) 
the "best wing system" concept to aircraft design, gave the name "PrandtlPlane" to the resulting aircraft Fig. 9, right).

One of the practical consequences of the improved aerodynamics is that the boxwing allows for an increase of the so-called span efficiency, one of the most significant parameters defining the lift-to-drag ratio of an aircraft, without increasing the wingspan.

Thinking at todays need of reducing the fuel consumption, hence the environmental impact, of aircraft, one of the possible approaches is acting on the aircraft architecture in order to improve the lift-to-drag ratio, also called aerodynamic efficiency. One of the ways to achieve such result is to improve the span efficiency by increasing the wingspan, which can be applied without any change to the architecture, hence by replacing in-service aircraft with larger ones, or introducing unconventional architectures such as truss-braced wings or folding wings, today also objects of research and development programs.

Aircraft with larger wingspan are good solutions as far as constraints from available apron space and other airport infrastructures are not taken into account, since they allow the increase of passenger numbers with the same amount of aircraft movements.

The PARSIFAL project has been carried out by the University of Pisa (Italy), in the role of coordinator, ONERA (France), the Delft University of Technology (Netherlands), ENSAM - Arts et Métiers (France), the DLR (Germany) and SkyBox Engineering, a SME from Italy. Although the PrandtlPlane configuration is suitable for different aircraft categories, the PARSIFAL project has been focused on short-tomedium haul aircraft, which typically feature a wingspan within $36 \mathrm{~m}$ as they belong to ICAO "C" category, such as the Airbus 320 or Boeing 737 aircraft. The reason for this choice is the fact that about $75 \%$ of passenger aircraft belong to this category, hence the compliance with such a standard implies a stronger impact.

The aerodynamic advantages of the box-wing have been utilised solely for the increase of passenger capacity (i.e. the payload) and not for an increase of cruise speed, the mission range, or other key performance parameters.

This requirement has been met by designing a double aisle fuselage specifically conceived for the box-wing system, with the result of increasing the number of maximum passengers from below 200 for the conventional aircraft to more than 300 in the PrandtlPlane case.

The possibility to increase the fuselage dimensions and, at the same time, keeping the $36 \mathrm{~m}$ wingspan constraint and obtaining a higher aerodynamic efficiency is a peculiarity of the box-wing system.

Starting from these two main choices, the consortium has carried out several design loops, adopting first low and medium fidelity tools and then refining the results by means of a multidisciplinary approach, in which high-fidelity tools have been used to perform aerodynamic analyses at both transonic and subsonic speeds, structural weight estimations, mass and balance characteristics evaluations, aeroelastic analyses, flight dynamic simulations, sizing of control surfaces, engine sizing and integration, landing gear sizing, etc. 
The same approach and same tools have been adopted to study the CeRAS CSR01 [24], a short range conventional reference aircraft which the PrandtlPlane has been compared to.

All the output obtained from these analyses have been then used to perform comparative impact assessment between the PrandtlPlane and the reference aircraft. In detail, these analyses have been focused on evaluating the atmospheric emissions during the whole mission and their influence on global warming, noise footprint during take-off and climb and associated psychoacoustic metrics, impact on turnaround time and airport logistics and, finally, the influence on direct operating costs and profitability from an airline point of view.

The most significant result is the following: increasing the number of passengers of about $50 \%$ allows for a reduction of fuel per passenger, hence emitted $\mathrm{CO}_{2}$, up to $22 \%$. As detailed in [24a], the associated Global Warming Potential, calculated on a 20 years horizon, would be reduced by about $17 \%$. In addition, the day-evening-night average level of noise is decreased for a given airport with assigned daily passengers traffic. On airport operations side, the turnaround of 300 passengers PrandtlPlane will be take only 5-10 min (depending on the considered operation scenario as defined in aircraft manufacturers' manuals, more than a 200 passengers conventional aircraft, e.g. outstation, full service, etc.) without any additional burden in terms of apron space or slots needed [24b]. Finally, direct costs per available seat-kilometer could be cut by about $12 \%$. Although the aircraft purchase cost would go up of about $60 \%$, the reduced direct operating cost would give the airlines the possibility to reach the same break-even point of conventional competitors with an average ticket price reduction of $13 \%$.

As said, these numbers come from the assumption of a growing market with some saturation constraints. For a more comprehensive analysis, the same comparisons have been performed considering a "less disruptive" 240 passengers PrandtlPlane, i.e. provided with a conventional single aisle fuselage (similar to the A321). By comparing the results with those of the reference conventional aircraft, similar margins of improvement have been estimated for both $\mathrm{CO}_{2}$ (about -20\%) and direct operating costs (about $-10 \%$ ). More details can be found in [24b-24d] and the official reports of the project $[25,26]$.

As a final remark, it is worth to underline that the achieved results do not take alternative fuels or alternative propulsion systems into account, but are only due to the box-wing architecture. Further investigations on the synergies between the boxwing and hydrogen-based or hybrid-electric propulsion systems are ongoing and will be a significant part of the future research on the PrandtlPlane.

\section{Sustainable SuperSonic Transport: Technical Challenges and Noise Certification}

Robert Jaron and Lars Enghardt 

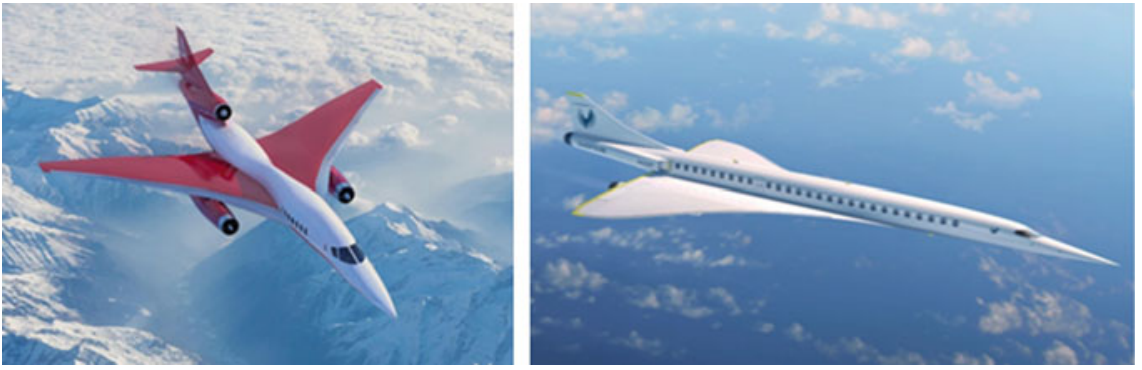

Fig. 10 Aerion Supersonic AS2 business jet (left @Aerion Supersonic) and Boom Supersonic Overture airliner (right $\odot$ Boom Supersonic)

About 25 years after Concord's last flight, commercial civilian supersonic aircraft may possibly enter the market once again as early as in the mid-2020s. Among others, two American manufacturers have announced an approaching market entry. Aerion Supersonic is designing a supersonic business jet cruising at Mach 1.4 with a cabin large enough for 12 passengers (Fig. 10). Boom Supersonic announced an airliner cruising at twice as fast as today's commercial airplanes and a passenger capacity up to $88 .^{1}$ It is expected that public acceptance for supersonic transport can only be achieved by concepts that are both sustainable and indistinguishable from subsonic aircraft in terms of their noise annoyance. Combining the high engine thrust required for supersonic cruise with sustainability poses a major challenge for manufacturers and researchers. Moreover, at the time being, there are no applicable noise certification standards for supersonic aircraft. Thus, the International Civil Aviation Organisation (ICAO, or national certification authorities) needs to define standards for the advent of this new generation of supersonic aircraft to ensure their public acceptance. With regard to noise emissions, two major challenges have to be tackled by establishing new certification standards in parallel to the technology development: Firstly, the landing and take-off (LTO) noise and secondly, the sonic boom and its impact on human beings.

The next generation of supersonic aircraft is expected to be restricted to flying subsonically over land, as technologies for so-called low-boom designs have not yet reached market readiness. The impact of supersonic booms caused by conventional designs on humans, animals, and building structures is still unacceptable. For that reason, flying supersonically over land is prohibited in several countries and even over water supersonic speed is only allowed with a sufficient buffer distance to the coastline, as secondary booms can propagate long distances depending on the prevailing atmospheric conditions. Thus, the major challenge of the next generation of supersonic aircraft will be to meet LTO noise levels comparable to subsonic aircraft. Supersonic aircraft are facing major tradeoffs between cruise performance and LTO noise. With regard to cruise performance, small engine diameters with high

\footnotetext{
${ }^{1}$ Aerion announced the termination of this AS2 business jet programme just when the present book was about to be edited. However, some similar concepts may appear again in the near future.
} 
jet speeds are required. This is because the pressure drag induced by the frontal crosssectional area increases considerably at transonic and supersonic cruise speeds. As a consequence, the volume distribution along the longitudinal axis of the aircraft is decisive for the wave drag. Using a design of three engines, the volumes can be distributed much more homogeneously with three small engines, one of which is placed in the vertical stabiliser. However, since installed jet noise scales approximately to the sixth power of jet speed, small engines with high jet speeds lead to very high LTO noise levels. Regarding the take-off certification procedure, there are substantial differences between subsonic and supersonic aircraft: Subsonic aircraft engines are dimensioned for takeoff conditions. In contrast, supersonic aircraft have the highest thrust requirements at top of climb leading to massive excess thrust at takeoff conditions. Given the tradeoff between LTO noise and cruise efficiency for supersonic aircraft, meeting the LTO noise targets will likely require not only technical developments, but also changes to the takeoff procedures specified in the noise regulation rules.

Already in 1979, Grantham and Smith [27] investigated LTO procedures of a supersonic airliner with a payload of 273 passengers cruising at Mach 2.62 for community noise abatement purposes. To reduce the flyover noise levels, they suggested a fast climb out at lower climb rate with higher speed. As supersonic aircraft have a significantly higher minimum drag speed, higher speeds allow a higher thrust cutback and in consequence a reduction of flyover EPNdB levels. To reduce sideline certification levels as well, they suggested a thrust reduction before the cutback point. The reduction level was limited in order to maintain the flight height or a four percent climb gradient for the emergency case of one engine being inoperative. Since then, this procedure has become known as programmed thrust lapse rate (PLR) takeoff. To ensure the same thrust reduction in daily operations and to relieve the pilot from too many actions during takeoff, only a fully automated FADEC (Full Authority Digital Engine Control) controlled thrust reduction should be considered for new certification procedures in addition to the allowance of a higher climb out speed $\mathrm{V}_{2}$. Recently, NASA and JAXA studied the acoustic advantage of the adjusted takeoff trajectory on a supersonic business jet with three engines, a cruise speed of Mach 1.4 and a MTOW of 45 [28, 29]. With 10\% PLR thrust reduction and a $15 \mathrm{kn}$ higher climb out speed $\left(\mathrm{V}_{2}+35 \mathrm{kn}\right)$, they found a cumulative EPNdB reduction in the order of $3 \mathrm{~dB}$. Nevertheless, the margin to the Chap. 14 noise regulation rules achieved was so small that other noise reduction features were investigated, as well. By enhancing the bypass ratio from 2.9 to 3.6, the cumulative noise benefit was estimated to be 5.3 EPNdB, albeit accompanied with a $4.1 \%$ penalty regarding the possible flight range. Using chevrons on engine exhausts, an estimated noise reduction potential of 2.7 EPNdB was identified, this time accompanied with a penalty of $2.8 \%$ in flight range. Another promising technical option to reduce jet noise is the so-called mixer ejector nozzle, which enables the virtual increase of the takeoff bypass ratio by injecting air from outside the engine into the jet through a variable opening to efficiently reduce the jet velocity. Variable mixer ejectors were investigated by NASA [30] and in the EU FP6 project HISAC with an expected benefit of approximately 7 EPNdB. Here, the identified drawback is an increased drag coefficient and extra weight. In view 
of these results, there is an urgent need for extensive research and development to adapt takeoff procedures and engine technologies in order to achieve the targeted noise levels at reasonable costs in terms of the anticipated flight range.

The second major challenge to establish supersonic aircraft on the market in the long term is the sonic boom. So far, there are two approaches of lowering the annoying pressure fluctuations impinging on the ground. Firstly, the so-called Mach cut-off procedure, where the airplane is flying just over Mach 1.0 but below Mach 1.15 For a steady standard atmosphere, flying in this very speed range will theoretically result in the sonic boom waveform not reaching the ground. Since this approach is strongly dependent on the atmospheric conditions as well as the uncertainties predicting these conditions, for the time being, it will quite likely not be allowed. The second possibility is a so-called low-boom design. After propagating through the atmosphere, the pressure signature of a conventional sonic boom has the very noisy and detrimental shape of a $\mathrm{N}$-wave. Due to a controlled nose shock with gradual pressure increase to the wing, the ground signature can be changed to a sine wave with lower gradients compared to shocks of conventional designs. Low-boom airframes are optimised to substantially lower the annoyance of the sonic boom. The objective of such optimisations is to minimise the human response to indoor and outdoor sonic boom predicted by accurate methods. Precise sonic boom prediction relies on the CFD simulation of the near field pressure field, the analytic propagation through the atmosphere considering atmospheric turbulence [31] and the modeling of the ground topology. In the H2020 project RUMBLE (2017-2020), different sonic boom prediction tools were developed and assessed [32]. The need for reliable sonic boom prediction has already been addressed in three workshops at the AIAA SciTech conference in 2014, 2017, and 2020 [33]. Regarding the human response one has to find an appropriate metric [34] but also conduct listening tests and sleep studies.

In 2021, two H2020 EU projects started with the aim to further improve the detailed assessment of supersonic aircraft on the one hand regarding LTO noise and on the other to investigate sonic boom. The projects will support the establishment of new certification standards ensuring sustainability and public acceptance of novel supersonic aircraft models. In the project SENECA (LTO noise and emissions of supersonic aircraft, 2021-2024), supersonic aircraft concepts will be designed and multidisciplinary optimised regarding airframe and engine architecture as well as the LTO trajectories. The aim is to reduce LTO noise and emissions as well as the global climate impact. In total, four different aircraft concepts will be examined: two business jets with cruise Mach numbers of 1.4 and 1.6 and two airliners cruising at Mach 2.0 and 2.2. The certification authorities will be given the scientific evidence to change the LTO procedure by handing over a comprehensive and reliable database of virtually flown landings and takeoffs with varying climb out speeds and thrust reductions before cutback and also with different aircraft and engine architectures, seeking for the lowest community noise. In particular various engine bypass ratios, the number of engines, the position of the engines as well as the nozzle and inlet geometry will be examined in terms of their tradeoffs between flight range and their noise reduction potential. The project MOREandLESS (MDO and Regulations for Low-boom and Environmentally Sustainable Supersonic Aviation, 2021-2024) will 
also investigate the sustainability of upcoming supersonic aircraft focusing on higher cruise Mach numbers starting with airliners cruising with Mach 2.2 going up to the hypersonic regime with Mach numbers of 5. In addition to the multidisciplinary optimisation of the aircraft concepts, experimental and numerical investigations of jet noise are envisaged. The impact of the aircraft shape on the sonic boom will be investigated by shooting projectiles in the shape of aircraft out of a gun on an outdoor testing track. The resulting sonic boom will be measured by microphones. Furthermore, to support the modeling of sound boom propagation and variability due to meteorology and turbulence in different environments, in rural areas and in urban areas, various measurements will be performed.

For the near future, a first low-boom flight demonstrator, the NASA x-59 is scheduled to make its first flights in 2022 in the USA. With regard to the global nature of air transport and with the difference between reactions of local communities, some flight tests may also be planned in Europe, in coordination with the European and EU national authorities for civil aviation. The NASA X-59 program based on the Lockeed-Martin QuietSST aircraft aims at proving low-boom technologies at large scale and gathering data on boom propagation and human response to the low-boom flight (Fig. 11).

In the long term, low-boom concepts will have to be scaled for higher payloads. Furthermore, one has to handle the integration of more than one engine to comply with civil aircraft safety regulations. Merging low-boom volume distributions with more than one engine and meeting LTO noise regulations will be the biggest challenge to finally achieve publicly accepted supersonic flight over land.

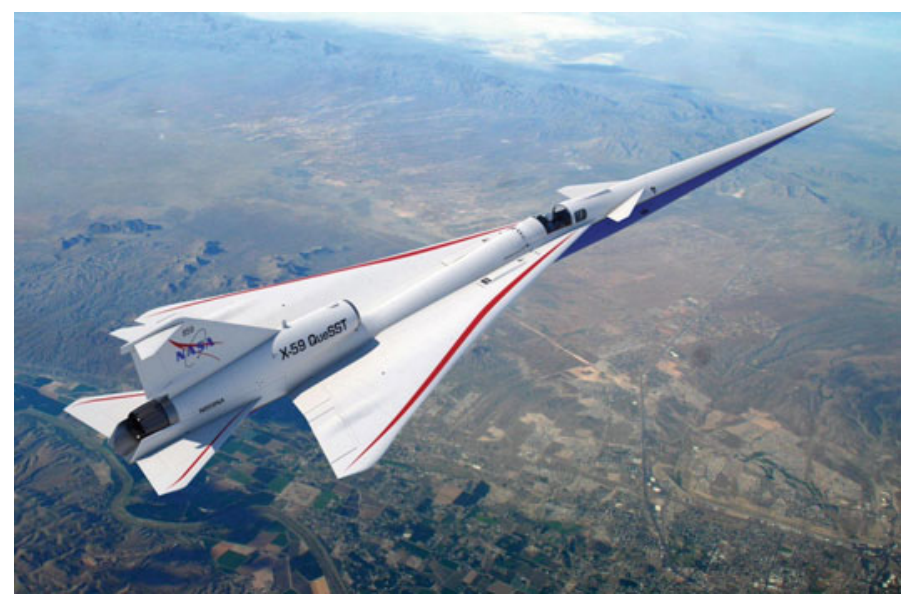

Fig. 11 NASA/Lockeed-Martin low-boom demonstrator X-59 (CLockeed-Martin) 


\section{Concluding Remarks}

The current chapter has presented only a small number of aircraft concepts which are currently under consideration for the improvement of efficiency and sustainability of future air transport.

Generally speaking, the research and development costs for future improvements are expected to be rather high. With current engine technology having reached a high level of maturity and complexity, the further increase in bypass ratio will be somehow limited by detrimental effects like drag, weight, (under wing) installation space etc. Geared turbofans have made a significant contribution by reducing the rotational speed of the fan at the cost of increased weight and cost for the gear itself. Future engine installations with bypass ratios of 16 or beyond will face integration issues and interaction effects as can be seen from inflow distortion effects for the BLI concept.

Open rotors instead of nacelle-mounted turbofan engines - which have not been discussed here - are another option for increased efficiency, but inhibit again the different noise characteristics demanding for adapted noise reduction technologies. The distributed propulsion - being driven by small turbo-prop engines or electric motors - are currently being considered at least for short-range aircraft (like the ARTEM-REBEL configuration). Here, the interaction and phasing effects are one of the major topics - beside the generation and distribution of electric energy for electrified versions. Electric driven propulsors are not necessarily "quiet" a priori, as the well-known fan noise sources and interactions are present as well. Moreover there are unknown effects of mutual interactions in the case of multiple propulsors.

For the aircraft fuselage, a clear trend towards lift-providing structures is visible which is consistent with the airframes of NOVA, BOLT, and REBEL presented here in the framework of the ARTEM project. TU Delft has pursued its "Flying V" - a variation of the blended wing concept [35]. AGILE, CENTRELINE, IMOTHEP and NACOR $[36,37]$ are recent or on-going EC funded projects which also deal with future aircraft configurations - mainly from performance and aerodynamic point of view.

For the introduction of disruptive configurations like the blended wing body, rather drastic changes are likely being required for current airport facilities, maintenance procedures, but also for design and manufacturing routines. So far, there is a certain lack of data and therefore in reliability of all predictions with respect to performance, aerodynamics, but especially also noise emissions of these configurations.

NASA and other institutions have made considerable efforts in the detailed assessment of current and future aircrafts. Khorrami and Fares [38] demonstrate these activities - including tools and simulation validation from sub-structures and wind tunnel models up to full scale-flight test with a Gulfstream research aircraft from aerodynamic and aero-acoustic perspective - the latter highlighted as being the more demanding. Spakovszky [39] provides a summary of activities ranging from quiet aircraft demonstrator (QAT), over the Silent Aircraft Initiative, to environmentally responsible aircraft (ERA) programs including also the well-known MIT-driven D8 
"double bubble" concept. The challenges are the same as briefly addressed in this chapter here: integration effects (like inflow distortion), shielding effects, and the modelling of noise reducing technologies. The interested reader can find a good list of current references on these programs' outcomes in [39].

Examining all these activities it becomes clear that, beside academic research by university and research centers, significant contributions from aircraft and engine manufacturers are needed in order to obtain higher TRL levels for the novel configurations. Airbus has recently revealed MAVERIC, a blended wing body demonstrator [40], which is likely to collect valuable validation data for future studies - thereby giving hope for the realisation of novel - more sustainable aircraft configurations in the coming decades. It must be also reminded that all those technological improvements have to be ultimately accepted by the market, i.e. the development and introduction are strongly dependent on regulations, and on the overall competitive advantage they may provide (where also noise reduction translates back to earned or saved money).

Acknowledgements The main authors wish to thank all contributors to this chapter - most coauthors are mentioned directly in conjunction with their respective contributions. The funding provided by the EC for the project ARTEM under grant number 769350 is gratefully acknowledged. Also, many other projects receive funding by the EC (grant numbers are given above). Finally, we would like to thank the ANIMA team for initiating the current book project and giving us the opportunity to share our views and findings on the future of air transport.

\section{References}

1. EEA (2018) Greenhouse gas-data viewer. https://www.eea.europa.eu/data-and-maps/data/ data-viewers/greenhouse-gases-viewer

2. EEA (2017) Trends and projections in Europe 2017, EEA Report No 17/2017. https://www. eea.europa.eu/publications/trends-and-projections-in-europe-2017

3. European Aviation Environmental Report 2019, Published by EEA, EASA, and EurControl. https://doi.org/10.2822/309946

4. Pierce B (2020) COVID-19 outlook for air transport and the airline industry. IATA, November 2020

5. Effects of novel coronavirus (COVID-19) on civil aviation: economic impact analysis. ICAO, February 2021

6. Wiart L, Atinault O, Boniface J-C, Barrier R (2016) Aeropropulsive performance analysis of the NOVA configurations. In: 30th congress of the international council of the aeronautical sciences, Daejeon, South Korea, September 2016. https://www.icas.org/ICAS_ARCHIVE/ ICAS2016/data/papers/2016_0092_paper.pdf

7. Wiart L, Atinault O, Grenon R, Paluch B, Hue D (2015) Development of NOVA aircraft configurations for large engine integration studies. In: 33rd AIAA applied aerodynamics conference, Dallas, TX, June 2015. ISBN 9781624103636; https://doi.org/10.2514/6.20152254, https://doi.org/10.2514/6.2015-2254.

8. Romani G (2020) Numerical analysis of fan noise for the NOVA boundary-layer ingestion configuration. Aerosp Sci Technol 96:105532. https://doi.org/10.1016/j.ast.2019.105532

9. Godard B, De Jaeghere E, Ben Nasr N, Marty J, Barrier R, Gourdain N (2017) A review of inlet-fan coupling methodologies. In: Proceedings of ASME Turbo Expo 2017, Paper GT2017-63577 
10. Lewy S, Polacsek C, Barrier R (2014) Analytical and numerical prediction of harmonic sound power in the inlet of aero-engines with emphasis on transonic rotation speeds. J Sound Vibr $333(26)$

11. Morino L, Bernardini G, Mastroddi F (2006) Multi-disciplinary optimisation for the conceptual design of innovative aircraft configurations. CMES 13(1):1-18. Tech Science Press

12. Iemma U, Diez M (2005) Optimal life-cycle-costs design of new large aircraft including the cost of community noise. In: ICCES 2005, IIT Madras, 1-6 December 2005, Chennai, India

13. Iemma U, Diez M, Marchese V (2006) Matching the aircraft noise to a target sound: a novel approach for optimal design under community noise constraints. In: 13th international congress on sound and vibration

14. Diez M, Iemma U (2012) Multidisciplinary conceptual design optimisation of aircraft using a sound-matching-based objective function. Eng Optimisation 591-612

14a. Centracchio F, Burghignoli L, Iemma U (2021) Multiobjective optimisation of flight paths for noise level mitigation and sound quality improvement. Noise Mapp 8(1):268-280. https:// doi.org/10.1515/noise-2021-0022

15. Centracchio F, Rossetti M, Iemma U (2018) Approach to the weight estimation in the conceptual design of hybrid-electric-powered unconventional regional aircraft. J Adv Transp

16. Burghignoli L, Centracchio F, Iemma U, Rossetti M (2018) Multi-objective optimisation of a BWB aircraft for noise impact abatement. In: 25th international congress on sound and vibration, ICSV25, Hiroshima, Japan

17. Bernardini $G$ et al (2020) Numerical characterisation of the aeroacoustic signature of propellers array for distributed electric propulsion. Special issue "Airframe noise and airframe/propulsion integration" of applied science (MDPI). Appl. Sci. 10(8):2643. https:// doi.org/10.3390/app10082643

18. Visingardi A, D'Alascio A, Pagano A, Renzoni P (1996) Validation of CIRA's rotorcraft aerodynamic modelling system with DNW experimental data. In: 22nd European rotorcraft forum, Brighton, UK

19. Barbarino M, Bianco D (2018) A BEM-FMM approach applied to the combined convected Helmholtz integral formulation for the solution of aeroacoustics problems. Comput Methods Appl Mech Eng. https://doi.org/10.1016/j.cma.2018.07.034

20. Centracchio F, Burghignoli L, Rossetti M, Iemma U (2018) Noise shielding models for the conceptual design of unconventional aircraft. In: 47th international congress and exposition on noise control engineering, Inter-Noise 2018, Chicago, Illinois, USA

21. Burghignoli L, Rossetti M, Centracchio F, Iemma U (2019) Noise shielding metamodels based on stochastic radial basis functions. In: Proceedings of the 26th international congress on sound and vibration, ICSV 2019

22. Centracchio F, Burghignoli L, Rossetti M, Iemma U (2018) Noise shielding models for the conceptual design of unconventional aircraft. In: INTER-NOISE 2018-47th international congress and exposition on noise control engineering: impact of noise control engineering

23. Prandtl L (1924) Induced drag of multiplanes. Technical Report TN 182, NACA 1924

24. CERAS CeRAS-CSR01: short range reference aircraft. https://ceras.ilr.rwth-aachen.de

24a. Tasca AL, Cipolla V, Abu Salem K, Puccini M (2021) Innovative box-wing aircraft: emissions and climate change. Sustainability 13:3282. https://doi.org/10.3390/su13063282

24b. Picchi Scardaoni M, Magnacca G, Massai A, Cipolla V (2021) Aircraft turnaround time estimation in early design phases: simulation tools development and application to the case of box-wing architecture. J Air Transp Manage 96. https://doi.org/10.1016/j.jairtraman.2021. 102122

24c. Abu Salem K, Cipolla V, Palaia G, Binante V, Zanetti D (2021) A physics-based multidisciplinary approach for the preliminary design and performance analysis of a medium range aircraft with box-wing architecture. Aerospace 8(10):292. https://doi.org/10.3390/aerospace 8100292

24d. Abu Salem K, Palaia G, Cipolla V, Binante V, Zanetti D, Chiarelli M (2021) Tools and methodologies for box-wing aircraft conceptual aerodynamic design and aeromechanic analysis. Mech Ind 22:39. https://doi.org/10.1051/meca/2021037 
25. PARSIFAL Project Consortium. Report on operational and economic assessment. PARSIFAL Project Deliverable D1.2, 2020 https://www.parsifalproject.eu/PARSIFAL_DOWNLOAD/ PARSIFAL_D12.pdf

26. PARSIFAL Project Consortium. PrandtlPlane performance analysis and scaling procedures. PARSIFAL Project Deliverable D3.4, 2020. https://www.parsifalproject.eu/PARSIFAL_ DOWNLOAD/PARSIFAL_D34.pdf

27. Grantham WD, Smith PM(1979) Development of SCR aircraft takeoff and landing procedures for community noise abatement and their impact on flight safety. Supersonic Cruise Research, pp 299-333

28. Akatsuka J, Ishii T (2020) System noise assessment of NASA supersonic technology concept aeroplane using JAXA's noise prediction tool. AIAA Scitech 2020 Forum

29. Berton JJ, Huff DL, Geiselhart K, Seidel J (2020) Supersonic technology concept aeroplanes for environmental studies. AIAA Scitech 2020 Forum

30. Hendricks E, Seidel J (2012) A multidisciplinary approach to mixer-ejector analysis and design. In: 48th AIAA/ASME/SAE/ASEE joint propulsion conference

31. Lazzara DS, Magee T, Shen H, Mabe JH (2020) Sonic boom performance of low-boom aircraft in non-standard atmospheres. AIAA Scitech 2020 Forum

32. Carrier G, Normand P, Malbequi P (2021) Analysis and comparison of the results of two ray tracing-based sonic boom propagation codes applied to the SBPW3 test cases. AIAA Scitech 2021 Forum

33. Rallabhandi SK, Loubeau A (2021) Summary of propagation cases of the third AIAA sonic boom prediction workshop. AIAA Scitech 2021 Forum

34. DeGolia J, Loubeau A (2017) A multiple-criteria decision analysis to evaluate sonic boom noise metrics. J Acoust Soc Am 141(5):3624

35. Flying V concept of TU Delft. https://www.airlineratings.com/news/future-travel-flying-vtakes-flight/. Last accessed on 9.3.2021

36. Méheut $\mathrm{M}$ et al (2020) Conceptual design studies of boundary layer engine integration concepts. In: Aerospace Europe conference 2020, 25-28 February 2020, Bordeaux, France

37. Iwanizki $\mathrm{M}$ et al (2020) Conceptual design studies of unconventional configurations. In: Aerospace Europe conference 2020, 25-28 February 2020, Bordeaux, France

38. Khorrami MR, Fares E (2019) Toward noise certification during design: airframe noise simulations for full-scale, complete aircraft. CEAS Aeronaut J 10:31-67. https://doi.org/10.1007/ s13272-019-00378-1

39. Spakovszky ZS (2019) Advanced low-noise aircraft configurations and their assessment: past, present, and future. CEAS Aeronaut J 10:137-157. https://doi.org/10.1007/s13272-019-003 71-8

40. https://www.airbus.com/newsroom/press-releases/en/2020/02/airbus-reveals-its-blendedwing-aircraft-demonstrator.html. Last accessed on 9.3.2021

Open Access This chapter is licensed under the terms of the Creative Commons Attribution 4.0 International License (http://creativecommons.org/licenses/by/4.0/), which permits use, sharing, adaptation, distribution and reproduction in any medium or format, as long as you give appropriate credit to the original author(s) and the source, provide a link to the Creative Commons license and indicate if changes were made.

The images or other third party material in this chapter are included in the chapter's Creative Commons license, unless indicated otherwise in a credit line to the material. If material is not included in the chapter's Creative Commons license and your intended use is not permitted by statutory regulation or exceeds the permitted use, you will need to obtain permission directly from the copyright holder.

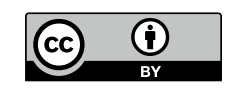

